\title{
A Systematic Review of the Effectiveness of Medical Cannabis for Psychiatric, Movement and Neurodegenerative Disorders
}

\author{
Keane Lim $^{1}$, Yuen Mei See ${ }^{1}$, Jimmy Lee ${ }^{1,2, *}$ \\ ${ }^{1}$ Research Division, Institute of Mental Health, ${ }^{2}$ Department of General Psychiatry 1, Institute of Mental Health, Singapore
}

\begin{abstract}
The discovery of endocannabinoid's role within the central nervous system and its potential therapeutic benefits have brought forth rising interest in the use of cannabis for medical purposes. The present review aimed to synthesize and evaluate the available evidences on the efficacy of cannabis and its derivatives for psychiatric, neurodegenerative and movement disorders. A systematic search of randomized controlled trials of cannabis and its derivatives were conducted via databases (PubMed, Embase and the Cochrane Central Register of Controlled Trials). A total of 24 reports that evaluated the use of medical cannabis for Alzheimer's disease, anorexia nervosa, anxiety, dementia, dystonia, Huntington's disease, Parkinson's disease, post-traumatic stress disorder (PTSD), psychosis and Tourette syndrome were included in this review. Trial quality was assessed with the Cochrane risk of bias tool. There is a lack of evidence on the therapeutic effects of cannabinoids for amyotrophic lateral sclerosis and dystonia. Although trials with positive findings were identified for anorexia nervosa, anxiety, PTSD, psychotic symptoms, agitation in Alzheimer's disease and dementia, Huntington's disease, and Tourette syndrome, and dyskinesia in Parkinson's disease, definitive conclusion on its efficacy could not be drawn. Evaluation of these low-quality trials, as rated on the Cochrane risk of bias tools, was challenged by methodological issues such as inadequate description of allocation concealment, blinding and underpowered sample size. More adequately powered controlled trials that examine the long and short term efficacy, safety and tolerability of cannabis for medical use, and the mechanisms underpinning the therapeutic potential are warranted.
\end{abstract}

KEY WORDS: Cannabis; Cannabinoids; Randomized controlled trial; Mental disorders; Movement disorders; Neurodegenerative diseases.

\section{INTRODUCTION}

Cannabis (marijuana) has long been used for medical and recreational purposes. The Cannabis sativa and Cannabis indica are two common species used for consumption. Between the two species, C. sativa has comparatively higher delta-9-tetrahydrocannabinol (THC) concentration while $C$. indica has comparatively higher cannabidiol concentration. Cannabinoids can be classified into three subtypes, endocannabinoids (naturally present in human body), phytocannabinoids (present in cannabis plant) and synthetic cannabinoids (produced chemically). Presently, over 60 different types of pharmacologically active cannabinoids have been identified and

Received: April 12, 2017 / Revised: July 6, 2017

Accepted: July 11, 2017

Address for correspondence: Jimmy Lee, MBBS, M Med (Psychiatry), $\mathrm{MCl}$, FAMS

Research Division, Institute of Mental Health, 10 Buangkok View, Singapore 539747

Tel: +65-63892000, Fax: +65-63891050

E-mail: Jimmy_lee@imh.com.sg isolated from the cannabis plant. ${ }^{1)}$ These include the exogenous cannabinoids such as the psychoactive THC and non-psychoactive cannabidiol, as well as the endogenous cannabinoids such as anandamide, which affects most systems in the human body, especially the central nervous system. The cannabinoid binds to two types of G protein-coupled receptors: $\mathrm{CB}_{1}$, which are most abundant in the brain, and $\mathrm{CB}_{2}$, which are expressed on cells in the immune system where inflammation is modulated. ${ }^{1)}$ Hence, cannabinoids are involved in psychomotor coordination, memory, mood, and pain. ${ }^{2}$ Given the expression of these receptors in the human body, and the interactions between cannabinoids with neurotransmitters and neuromodulators, such as dopamine, glutamate, serotonin, gamma-aminobutyric acid (GABA), it has been thought that cannabis may potentially confer some degree of medical benefit.

Medical cannabis refers to the use of cannabis and its derivatives to treat disease and relieve symptoms. ${ }^{3)}$ Common commercially available cannabinoids for medical use are presented in Table 1. ${ }^{4-6)}$ Testing of other synthetic cannabinoid compounds such as Epidiolex (GW

(c) This is an Open-Access article distributed under the terms of the Creative Commons Attribution Non-Commercial License (http://creativecommons.org/licenses/by-nc/4.0) which permits unrestricted non-commercial use, distribution, and reproduction in any medium, provided the original work is properly cited. 
Table 1. Summary of cannabinoids

\begin{tabular}{|c|c|c|c|c|c|}
\hline $\begin{array}{c}\text { Generic } \\
\text { name }\end{array}$ & $\begin{array}{l}\text { Trade } \\
\text { name }\end{array}$ & $\begin{array}{l}\text { Administration } \\
\text { method }\end{array}$ & Formulation & Dosage & Pharmacokinetics \\
\hline Dronabinol & Marinol & Oral capsule & Synthetic THC & $2.5 \mathrm{mg}, 5 \mathrm{mg}, 10 \mathrm{mg}$ & $\begin{array}{l}t_{\max }=2-4 \mathrm{hr} . \text { Completely absorbed } \\
\quad(90-95 \%) \text { after a single dose } \\
\text { Alpha (plasma) half-life: } 4 \mathrm{hr} \\
\text { Beta (tissue) half-life: } 25-36 \mathrm{hr}^{*}\end{array}$ \\
\hline Nabilone & Cesamet & Oral capsule & $\begin{array}{l}\text { Synthetic structural analogue of } \\
\text { THC } \\
\text { Methylgroup at C9 and pentyl side } \\
\text { chain in THC substituted with a } \\
\text { ketone group and a dimethyl } \\
\text { heptyl side chain respectively. }\end{array}$ & $1 \mathrm{mg}$ & $\begin{array}{l}t_{\max }=2 \mathrm{hr} \\
\text { Alpha (plasma) half-life: } 2 \mathrm{hr} \\
\text { Beta (tissue) half-life: } 35 \mathrm{hr}^{*}\end{array}$ \\
\hline Nabiximols & Sativex & $\begin{array}{l}\text { Oromucosal } \\
\text { spray }\end{array}$ & Whole plant cannabis extract & $\begin{array}{l}2.7 \mathrm{mg} \text { THC and } 2.5 \\
\text { mg CBD, per } \\
\text { spray }(100 \mu \mathrm{l})\end{array}$ & $\begin{array}{l}t_{\max }=98-253 \mathrm{~min} \\
\text { Variable plasma half-life of } 85-130 \mathrm{~min} \\
\text { Clearance within } 12-24 \mathrm{hr} \text { after dose* }\end{array}$ \\
\hline $\mathrm{CBD}$ & None & Oral capsule & Cannabis plant extract & Variable & No available information in humans ${ }^{4)}$ \\
\hline THC & Namisol & Oral capsule & Cannabis plant extract & Variable & $\begin{array}{l}t_{\max }=1-2 \mathrm{hr} \\
\text { Half-life: } 72-80 \min ^{5,6)}\end{array}$ \\
\hline
\end{tabular}

THC, tetrahydrocannabinol; CBD, cannabidiol.

*Marinol (Abbott Products, 2010), Cesamet (Valeant Canada, 2009), and Sativex (GW Pharmaceutical, 2010).

Pharmaceuticals, Cambridge, UK), Namisol (Echo Pharmaceuticals, Weesp, the Netherlands) and Cannador (Society for Clinical Research, Berlin, Germany) are currently underway. These cannabinoid formulations of varying THC or cannabidiol concentration and/or ratio have been widely studied for a variety of illnesses, most notably somatic conditions like pain and spasticity. ${ }^{3)}$ More recently, there has been a growing interest in the neuroprotective potential of cannabinoids for neurological conditions, and the antipsychotic properties of cannabidiol. Preclinical evidences suggest that cannabinoids may attenuate neurodegeneration by reducing excitotoxicity and oxidative damage via $\mathrm{CB}_{1}$ and $\mathrm{CB}_{2}$ receptors and receptor-independent mechanisms. ${ }^{7,8)}$ In the case of cannabidiol, there are indications that cannabidiol modulates the endocannabinoids system by enhancing anandamine levels, thereby reducing psychotic symptoms. ${ }^{9}$ Although reviews of preclinical and clinical studies have been conducted on movement disorders ${ }^{8)}$ and psychosis, ${ }^{10,11)}$ the aim of the present review is to provide a more in-depth evaluation of the efficacy of medical cannabinoids by appraising the quality of evidences from clinical studies across a broader range of neurodegenerative disorders and psychiatric conditions.

\section{METHODS}

\section{Types of Studies}

Randomized controlled trials that compared and examined the pharmacological intervention of cannabis (in any preparation form, and any route of administration) with placebo or other active treatments were included. Other quantitative study designs such as cohort studies, retrospective chart review studies, and case studies were excluded. Opinion and discussion papers were also excluded. This review only considered studies on human participants that were published in English-language.

\section{Types of Participants}

People of any age and sex with any of the following conditions, and/or clinically diagnosed with movement disorders (e.g., dystonia, Huntington's disease, Parkinson's disease, Tourette syndrome), neurological conditions (e.g., Alzheimer's disease, dementia, amyotrophic lateral sclerosis [ALS]) and psychiatric condition (e.g., psychosis, schizophrenia, anxiety).

\section{Types of Interventions}

Any form of cannabis for medical use irrespective of the route of administration, duration of intervention or dosage: Smoked cannabis, natural or synthetic cannabinoid including, THC, cannabinol (CBN), cannabidiol, or combinations of abovementioned agents. The comparators included placebo, usual care, other types of active treatments, or derivatives of cannabis.

\section{Search Strategy}

An electronic search of human studies published in English-language was conducted in PubMed, Embase, and the Cochrane Central Register of Controlled Trials 
(CENTRAL) from its inception to present (April 2017), using the following keywords: "randomized controlled trial (RCT), cannabinoids, cannabis, tetrahydrocannabinol, THC, cannabidiol, movement disorder, neurodegenerative, psychiatric, dystonia, Huntington's disease, Parkinson's disease, Tourette syndrome, Alzheimer's disease, dementia, ALS, psychosis, schizophrenia, anxiety". The reference lists of retrieved papers were also reviewed for additional papers. The full texts retrieved were assessed for relevance based on the objectives and inclusion criteria of this review. Studies in which full text were unavailable were excluded.

\section{Data Extraction and Quality Assessment}

The data extracted from each report included the study type, sample characteristics, type and dosage of intervention, primary outcome measures, side effect and adverse events. Studies were evaluated for methodological quality using the Cochrane risk of bias tool, ${ }^{12)}$ on sequence generation, allocation concealment, blinding, incomplete data and selective outcome reporting. The ratings were high, low or unclear risk of bias (Table $2^{13-36)}$ ). The assessment of methodological quality was performed by two independent raters. Discrepancies were resolved by mutual discussion.

Table 2. Cochrane risk of bias tool ratings of included studies

\begin{tabular}{|c|c|c|c|c|c|c|c|}
\hline \multirow[b]{2}{*}{ Study } & \multicolumn{7}{|c|}{ Cochrane risk of bias tool } \\
\hline & $\begin{array}{l}\text { Random } \\
\text { sequence } \\
\text { generation }\end{array}$ & $\begin{array}{c}\text { Allocation } \\
\text { concealment }\end{array}$ & $\begin{array}{l}\text { Blinding of } \\
\text { participant/ } \\
\text { personnel }\end{array}$ & $\begin{array}{l}\text { Blinding of } \\
\text { outcome } \\
\text { assessment }\end{array}$ & $\begin{array}{c}\text { Incomplete } \\
\text { outcome } \\
\text { data }\end{array}$ & $\begin{array}{l}\text { Selective } \\
\text { reporting }\end{array}$ & Overall \\
\hline \multicolumn{8}{|l|}{ Psychiatric condition } \\
\hline \multicolumn{8}{|l|}{ Anorexia Nervosa } \\
\hline Gross et al. $(1983)^{13)}$ & $?$ & $?$ & $?$ & $?$ & $?$ & - & - \\
\hline Andries et al. (2014) & + & + & + & + & + & + & + \\
\hline \multicolumn{8}{|l|}{ Anxiety } \\
\hline Fabre et al. $(1981)^{15)}$ & $?$ & - & - & - & - & $?$ & - \\
\hline Glass et al. $(1981)^{16)}$ & $?$ & $?$ & - & - & $?$ & $?$ & - \\
\hline Zuardi et al. $(1982)^{17)}$ & $?$ & $?$ & $?$ & $?$ & + & + & $?$ \\
\hline Bergamaschi et al. $(2011)^{18)}$ & - & - & + & $?$ & + & + & - \\
\hline Crippa et al. $(2011)^{19)}$ & $?$ & $?$ & $?$ & $?$ & + & + & $?$ \\
\hline \multicolumn{8}{|l|}{ Post-traumatic stress disorder } \\
\hline Jetly et al. $(2015)^{20)}$ & $?$ & $?$ & + & + & + & + & $?$ \\
\hline \multicolumn{8}{|l|}{ Psychotic symptoms } \\
\hline Leweke et al. $(2012)^{21)}$ & + & $?$ & $?$ & $?$ & + & - & - \\
\hline \multicolumn{8}{|l|}{ Neurodegenerative disorders } \\
\hline \multicolumn{8}{|l|}{ Alzheimer's disease } \\
\hline Volicer et al. $(1997)^{22)}$ & $?$ & $?$ & $?$ & $?$ & $?$ & + & $?$ \\
\hline \multicolumn{8}{|l|}{ Dementia } \\
\hline Walther et al. $(2011)^{23)}$ & $?$ & $?$ & $?$ & $?$ & + & $?$ & $?$ \\
\hline van den Elsen et al. $(2015)^{24)}$ & + & $?$ & + & + & $?$ & + & $?$ \\
\hline van den Elsen et al. $(2015)^{25)}$ & + & $?$ & + & + & $?$ & + & $?$ \\
\hline \multicolumn{8}{|l|}{ Amyotrophic lateral sclerosis } \\
\hline Weber et al. $(2010)^{26)}$ & + & $?$ & + & + & + & + & $?$ \\
\hline \multicolumn{8}{|l|}{ Movement disorders } \\
\hline \multicolumn{8}{|l|}{ Dystonia } \\
\hline Fox et al. $(2002)^{27)}$ & + & + & $?$ & $?$ & $?$ & $?$ & $?$ \\
\hline Zadikoff et al. $(2011)^{28)}$ & + & $?$ & $?$ & $?$ & - & + & - \\
\hline \multicolumn{8}{|l|}{ Huntington's disease } \\
\hline Consroe et al. $(1991)^{29)}$ & $?$ & $?$ & + & + & $?$ & + & $?$ \\
\hline Curtis et al. (2009) ${ }^{30)}$ & $?$ & + & $?$ & $?$ & + & + & $?$ \\
\hline López-Sendón Moreno et al. (2016) & + & $?$ & + & + & + & + & $?$ \\
\hline \multicolumn{8}{|l|}{ Parkinson's disease } \\
\hline Sieradzan et al. $(2001)^{32)}$ & $?$ & $?$ & $?$ & $?$ & $?$ & + & $?$ \\
\hline Carroll et al. $(2004)^{33)}$ & + & $?$ & + & + & + & + & $?$ \\
\hline Chagas et al. $(2014)^{34)}$ & $?$ & $?$ & + & + & + & + & $?$ \\
\hline \multicolumn{8}{|l|}{ Tourette syndrome } \\
\hline Müller-Vahl et al. (2002) & $?$ & $?$ & + & + & + & + & $?$ \\
\hline Müller-Vahl et al. (2003) ${ }^{36)}$ & $?$ & $?$ & + & + & - & + & - \\
\hline
\end{tabular}

+ , low risk of bias; -, high risk of bias; ?, unclear risk of bias. 


\section{RESULTS}

The search yielded 931 records (hits), of which 916 records remained after removing duplicates. Eighty-six records were then considered as potentially relevant after evaluation of title and abstract. The reference lists of these records were also reviewed. The full texts of these records were retrieved and reviewed based on the inclusion criteria and objectives of this review. A total of 62 records were excluded and 24 records were included in this review (Fig. 1). ${ }^{37)}$ Of the 24 reports (480 participants), 18 were crossover trials, 6 were parallel trials. All of the studies were conducted in Western societies.

\section{Psychiatric Disorders}

\section{Anorexia nervosa}

Two studies (36 participants), rated as having an low and high risk of bias, evaluated cannabinoids for the treatment of anorexia nervosa. ${ }^{13,14)}$ In an early crossover trial involving 11 females with anorexia nervosa, titrated THC $7.5 \mathrm{mg}$ ( $2.5 \mathrm{mg}$, three times a day) to a maximum of $30 \mathrm{mg}$ (10 mg, three times a day) showed similar weight gain to titrated diazepam $3.0 \mathrm{mg}$ ( $1 \mathrm{mg}$, three times a day) to 15.0 $\mathrm{mg}$ ( $5 \mathrm{mg}$, three times a day). Three patients in the THC treated group were withdrawn due to severe dysphoric reactions. More recently, in two 4-week treatments separated by a 4-week washout period, dronabinol $(2.5 \mathrm{mg}$, twice a day) produced significant weight gain of $0.73 \mathrm{~kg}(p<$ 0.01 ), compared to placebo. ${ }^{14)}$

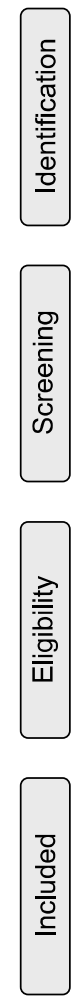

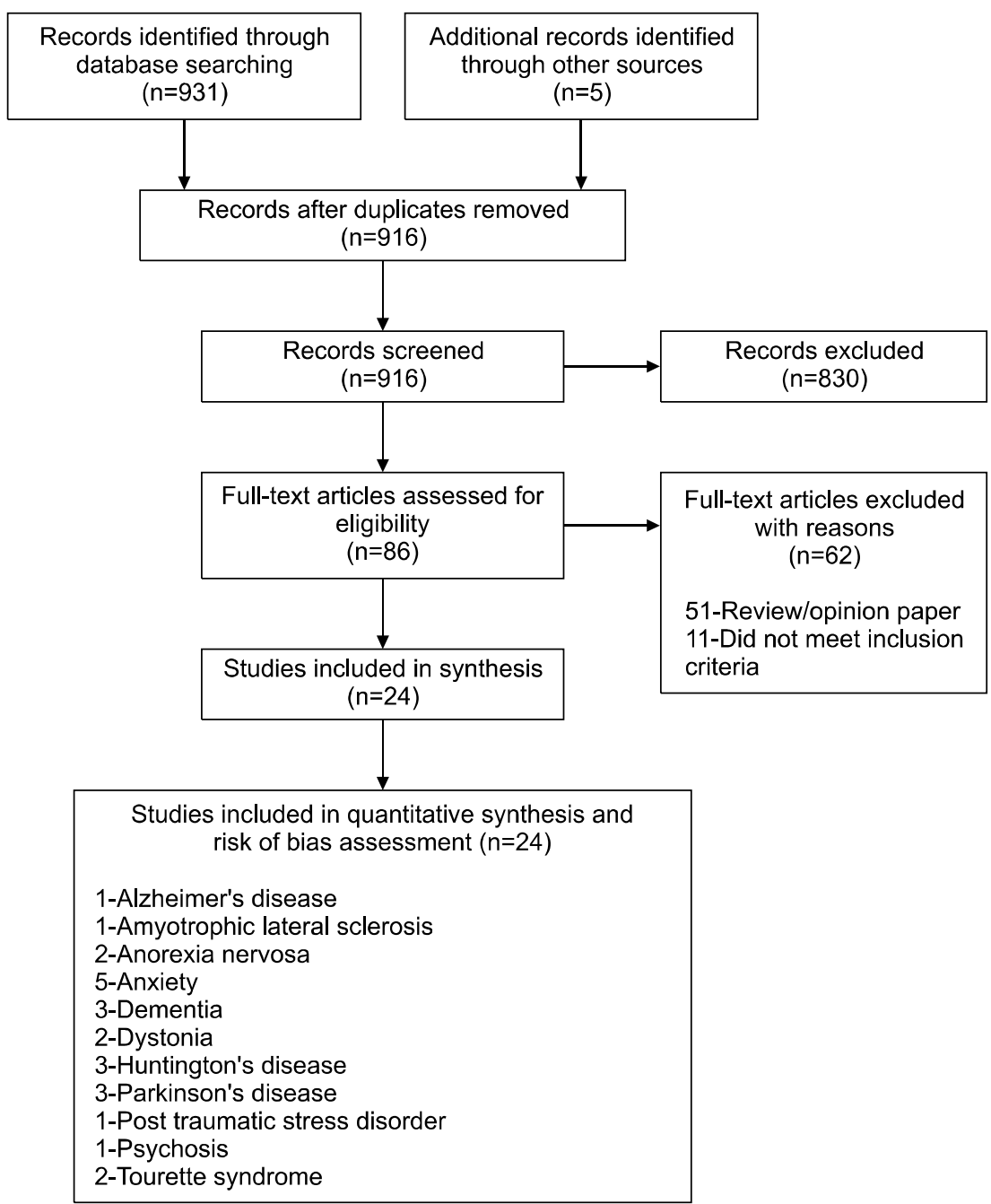

Fig. 1. Flow diagram of study review process - PRISMA flow chart. ${ }^{37)}$ 


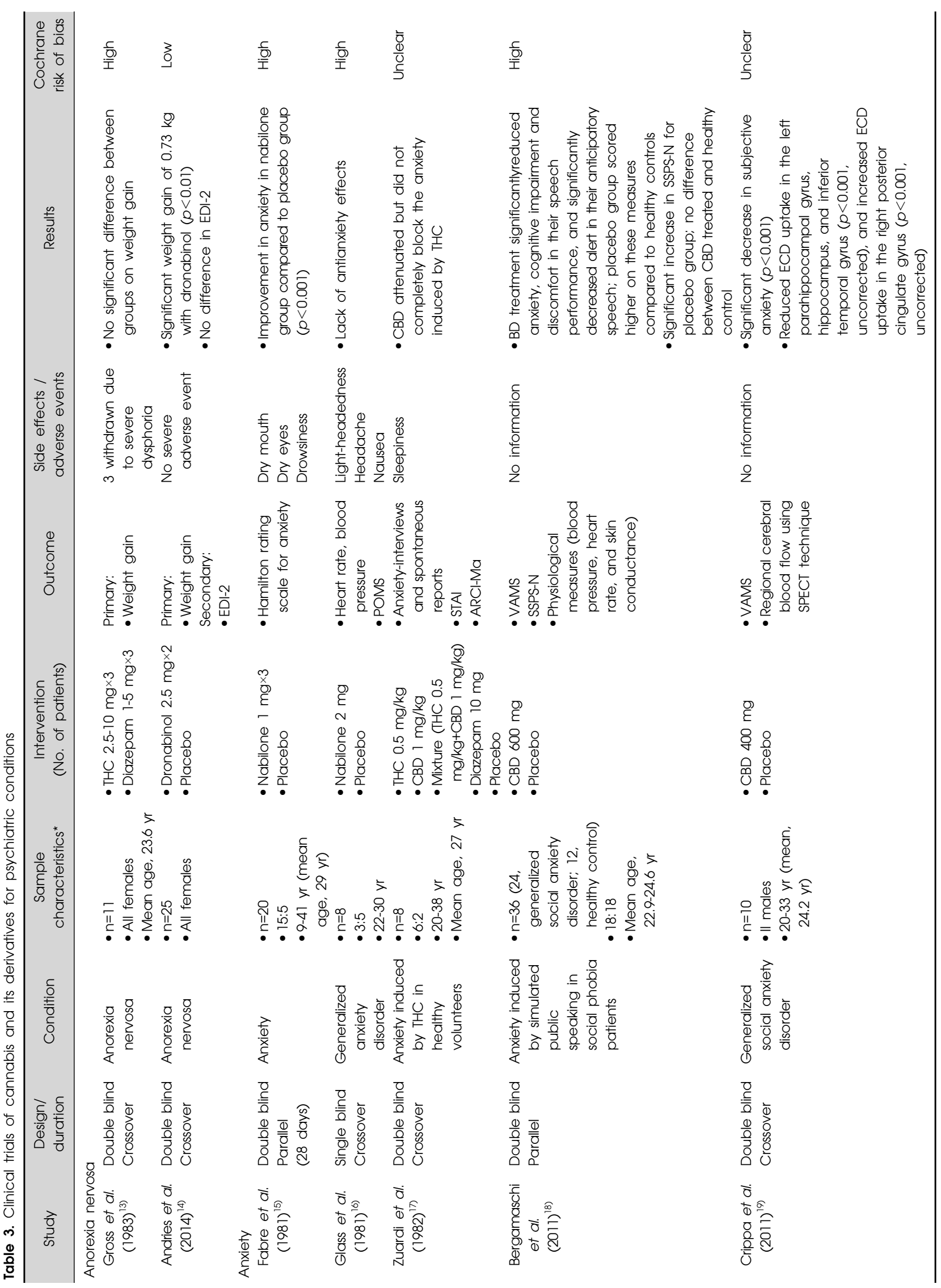


Anxiety

The anti-anxiety efficacy of cannabinoids was assessed in 5 studies ${ }^{15-19)}$ involving a total of 38 patients and 44 healthy volunteers (Table 3 ). Three studies were rated as high risk of bias and 2 as unclear risk of bias. Two early studies indicated equivocal anti-anxiety effects of nabilone. ${ }^{15,16)}$ Specifically, in a double-blind study involving 20 patients, compared to placebo, $1 \mathrm{mg}$ nabilone administered twice daily for 28 days significantly improved anxiety measured by the Hamiliton Rating Scale for Anxiety. ${ }^{15)}$ However, this was not observed in another study involving 8 symptomatic volunteers. ${ }^{16)}$ In another crossover trial involving 8 healthy volunteers with a history of cannabis use, cannabidiol attenuated anxiety induced by THC. ${ }^{17)}$ More recently, in a parallel study, 24 generalized social anxiety disorder patients were randomized to receive either a single dose of $600 \mathrm{mg}$ cannabidiol or placebo, and were also subjected to a simulated public speaking test. ${ }^{18)}$ Pre-treatment of cannabidiol significantly reduced anxiety measured by the visual analogue mood scale. In a another crossover trial involving 10 male patients with generalized social anxiety disorder, a single dose of $400 \mathrm{mg}$ cannabidiol was associated with a significant decrease in subjective anxiety measured by the visual analogue mood scale $(p<0.001) .{ }^{19)}$

Post-traumatic stress disorder (PTSD)

In a first randomized controlled crossover trial on PTSD, 10 males with PTSD associated nightmares were administered with titrated 0.5 to $3.0 \mathrm{mg}$ nabilone or placebo, in two 7-week treatment periods, separated by a 2-week washout period. ${ }^{20)}$ Compared to placebo, nabilone significantly $(p=0.03)$ reduced nightmares as measured by the Clinicians-administered PSTD scale. Furthermore, the Clinical Global Impression of Change (CGI-C) indicated

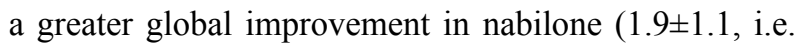
much improved) than placebo group ( $3.2 \pm 1.2$, i.e. minimally improved). This study was rated as having an unclear risk of bias.

\section{Psychotic symptoms}

To date, only one published trial investigated the antipsychotic properties of cannabidiol in patients with schizophrenia. ${ }^{21)}$ This study was rated as high risk of bias. In this 4-week parallel, active-controlled trial, 42 patients with schizophrenia were randomized to receive either cannabidiol or amisulpride (up titration of $200 \mathrm{mg}$ per day each, to a daily dose of $200 \mathrm{mg}$ four times daily). ${ }^{21)}$ While significant clinical improvements were observed in both 


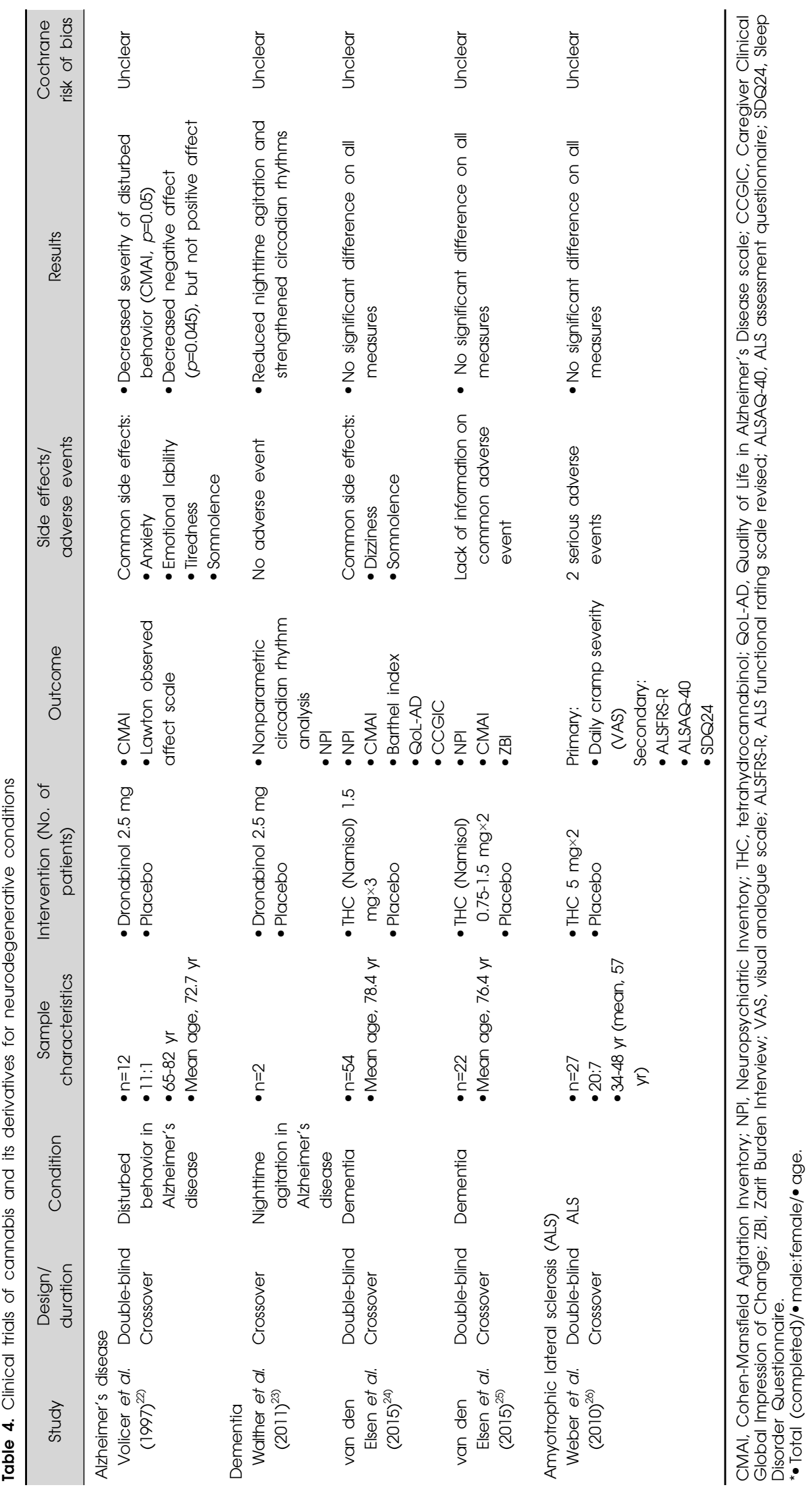


treatments as indexed by the Brief Psychiatric Rating Scale and the Positive and Negative Syndrome Scale, no statistical significant difference was reported between groups. However, cannabidiol treatment displayed a superior side-effect profile, compared to amisulpride treatment. Specifically, cannabidiol was associated with significantly smaller weight gain, lower prolactin levels and lesser extrapyramidal symptoms.

\section{Neurodegenerative Disorders}

\section{Alzheimer's disease}

One trial on Alzheimer's disease, rated as unclear risk of bias, examined the use of dronabinol for managing Alzheimer's disease (Table 4). ${ }^{22)}$ In a 6-week crossover trial, $2.5 \mathrm{mg}$ dronabinol appeared to reduce disturbed behaviors in 12 patients, as measured by the Cohen-Mansfield Agitation Inventory $(p=0.05){ }^{22)}$

\section{Dementia}

Three trials on dementia (78 participants), rated as having an unclear risk of bias, showed equivocal results. In a 4-week trial, $2.5 \mathrm{mg}$ dronabinol reduced night-time agitation and strengthened circadian rhythms in the 2 patient enrolled in the study. ${ }^{23)}$ However, two recent trials on showed that THC capsules (0.75-1.5 mg) did not improve neuropsychiatric symptoms in patients with dementia. ${ }^{24,25)}$

\section{Amyotrophic lateral sclerosis}

The only RCT was conducted in 27 patients with ALS. $^{26)}$ In this crossover trial, patients were randomized to receive 2 weeks of $5 \mathrm{mg}$ THC twice daily or placebo, separated by a 2-week washout period. There is a lack of treatment effect on cramp intensity and number of cramps. This study was rated as having an unclear risk of bias.

\section{Movement Disorders}

\section{Dystonia}

Two trials ${ }^{27,28)}$ (24 participants) indicated lack of evidence on the use of cannabinoid for dystonia (Table 5). The studies were rated as having an unclear risk of bias and high risk of bias. In a crossover trial, 15 patients with primary dystonia received a single dose of $0.03 \mathrm{mg} / \mathrm{kg}$ nabilone or placebo. ${ }^{27)}$ Although four patients reported a subjective improvement in dystonia severity, there was no significant difference between groups on the primary endpoint at 60,120 or 180 minutes post-treatment, as indexed by the Burke-Fahn-Marsden dystonia scale. In another 8-week crossover trial, 9 female patients with cervical dystonia were randomized to receive titrated $2.5 \mathrm{mg}$ dronabinol, up to 3 tabs twice a daily $(15 \mathrm{mg} /$ day) or placebo. $^{28)}$ There was no significant treatment effect of dronabinol on cervical dystonia as indexed by the Toronto Western Hospital Spasmodic Torticollis Rating Scale, or any of the secondary measures.

\section{Huntington's disease}

The efficacy of cannabinoids for Huntington's disease was assessed in 3 trials (84 participants). ${ }^{29-31)}$ All studies were rated as having an unclear risk of bias. A 6-week crossover trial evaluated cannabidiol (a total of $10 \mathrm{mg} / \mathrm{kg}$ over two doses daily) for chorea in 15 patients with Huntington's disease. There was no significant difference between placebo and cannabidiol on chorea severity measured by the Marsden and Quinn's Chorea Severity Scale. Conversely, in another 10-week placebo-controlled crossover trial, nabilone (1 or $2 \mathrm{mg}$ ) showed significant treatment effect as measured by the total motor and chorea score on the Unified Huntington's Disease Rating Scale (UHDRS). ${ }^{30)}$ More recently, no significant treatment effect was reported on the UHDRS, in a sample of 25 patients who receive nabiximols (up to 12 sprays/day) in a crossover trial. ${ }^{31 \text { ) }}$

\section{Parkinson's disease}

Three studies (49 participants) examined the use of cannabinoids for Parkinson's disease. ${ }^{32-34)}$ All studies were rated as having an unclear risk of bias. In an early crossover trial involving 9 Parkinson's disease patients with dyskinesia, $0.03 \mathrm{mg} / \mathrm{kg}$ nabilone significantly improved dyskinesia as indexed by the Rush dyskinesia disability scale. Conversely, in a 4-week dose escalation crossover trial, 19 Parkinson's disease patients with levodopa-induced dyskinesia were administered with titrated cannador up to $0.25 \mathrm{mg} / \mathrm{kg}$ THC or placebo. ${ }^{33)}$ Cannador failed to show any significant treatment effect on the primary outcome, the Unified Parkinson's Disease Rating Scale (UPDRS) dyskinesia items, as well as the secondary measures such as motor symptoms and quality of life (39-item Parkinson's disease questionnaire, PDQ-39). More recently, in a placebo-controlled trial, 21 patients with Parkinson's disease were randomized to receive cannabidiol $(75 \mathrm{mg} /$ day or $300 \mathrm{mg} /$ day) or placebo for 6 weeks. There was no statistical significant difference between the groups on the UPDRS. However, a significant improvement was reported for PDQ-39, particularly the activities of daily living and stigma subscale for the 300 $\mathrm{mg}$ /day cannabidiol group. ${ }^{34)}$ 


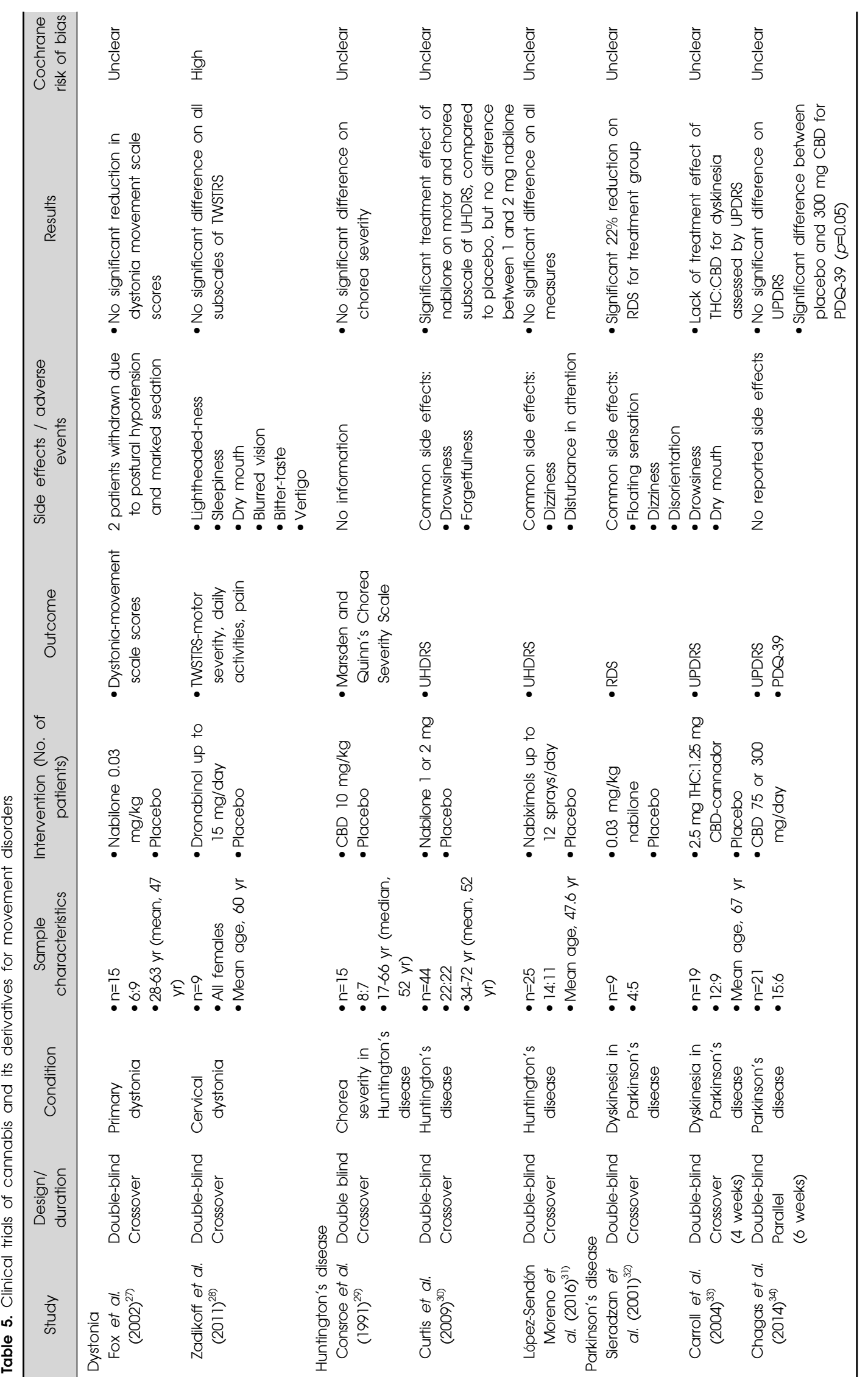




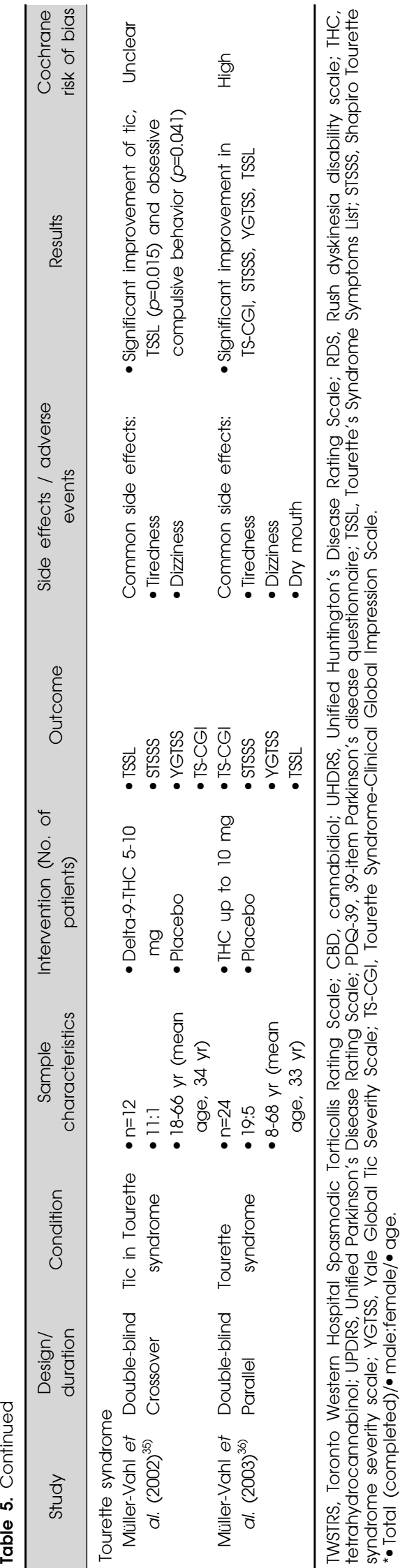

\section{Tourette syndrome}

Only two controlled trials (36 participants) evaluated the efficacy of cannabinoid for Tourette syndrome. ${ }^{35,36)}$ The studies were rated as having a high and unclear risk of bias. In a placebo-controlled crossover trial, 12 patients with Tourette syndrome received a single dose of THC 5 to $10 \mathrm{mg}$ (dose based on body weight). Using the Tourette Syndrome Symptom List, there was a significant treatment effect of THC on the subscale of tics $(p=0.015)$ and obsessive-compulsive behavior $(p=0.041)$. Mild adverse reactions such as dizziness, headache and mood changes were reported in 5 patients. In another 6-week trial from the same research group, 24 patients with Tourette syndrome were given oral THC up to $10 \mathrm{mg}$ per day. ${ }^{36)}$ Similarly, THC significantly reduced tic compared to placebo.

\section{DISCUSSION}

There is a lack of evidence on the therapeutic effects of cannabinoids for ALS and dystonia. Although results were inconsistent, there appears to be some low quality evidence of cannabinoids for anorexia nervosa, anxiety, PTSD, psychotic symptoms, agitation in Alzheimer's disease and dementia, Huntington's disease, and Tourette syndrome, and dyskinesia in Parkinson's disease. However, concrete conclusion of its efficacy could not be made due to the unclear risk of bias presented by these trials, as rated on the Cochrane risk of bias tool. Methodological issues such as inadequate description of allocation concealment and blinding, varying cannabinoid formulations and doses, and small sample sizes limit its potential clinical utility.

Consistent with previous case studies ${ }^{38,39)}$ and experimentally-controlled studies, ${ }^{40)}$ the only RCT on cannabidiol and psychosis showed promising results on the antipsychotic potential of cannabidiol. ${ }^{21)}$ Specifically, clinical symptoms negatively correlated with anandamide, an endogenous cannabinoid. It has been hypothesized that cannabidiol enhances anandamide signaling by indirectly blocking enzyme fatty acid amide hydrolase, resulting in an inhibition of anandamide degradation. Although the biological pathways of cannabidiol and anandamide is still unclear, and various potential mechanisms of action have been proposed, ${ }^{10)}$ the protective role of anandamine for psychotic symptoms could potentially be a new viable antipsychotic mechanism. Nonetheless, more adequately powered clinical trials evaluating the ef- 
fect of varying doses, and long term safety and efficacy are needed to supplement current findings.

For trials involving movement and neurodegenerative disorder, the limited number of trials, lack of quantitative data and underpowered samples inhibits reliable conclusion from being made. Nonetheless, the expression of endocannabinoid receptors $\left(\mathrm{CB}_{1}\right.$ and $\left.\mathrm{CB}_{2}\right)$ in the basal ganglia and the immune systems could indicate the protective role of cannabinoids for movement and neurodegenerative disorder. This warrants future studies, in vivo and animal models, to clarify the biological mechanisms underpinning the modulatory role of cannabinoids.

Cannabinoids appear to be well-tolerated in these trials. The common short-term effects included dry mouth, dizziness, tiredness, and headache. Indeed, reviews that discussed the adverse effect of cannabis administration have reported that cannabis or cannabinoid administration was associated with a greater risk of non-serious adverse events. ${ }^{3,41)}$ This illuminates the need to conduct trials that compare the effects and efficacy of cannabinoids with existing treatment. This would provide a clear cost-benefit evaluation of medical cannabis.

Overall, there are few RCTs that evaluated the efficacy of cannabis for psychiatric, neurodegenerative and movement disorders. While inconsistency in results may be attributed to different outcome measures used, varying doses and formulations, it raises the question on the mechanism underlying the therapeutic benefits of cannabinoids across indications with different pathophysiology (i.e., psychiatric, neurodegenerative and somatic conditions). Clarification of the cellular pathways and mechanisms of cannabinoids for various indications could reveal the cascading effect of cannabinoids and its interactions with pathways associated with these indications.

\section{CONCLUSION}

While there are trials that suggest potential benefit of cannabinoids for anorexia nervosa, anxiety, PTSD, psychotic symptoms agitation in Alzheimer's disease and dementia, Huntington's disease, and Tourette syndrome, and dyskinesia in Parkinson's disease, insufficient conclusion could be made due to the low quality of evidence as indexed by the Cochrane risk of bias, and underpowered samples. An improved knowledge of the precise mechanism of cannabinoids at the cellular level could provide insights on the therapeutic benefits of cannabinoids for movement, psychiatric and neurodegenerative disorder. This could facilitate development of cannabinoid for- mulations and the conduct of clinical trials on these indications.

\section{Acknowledgments}

This research is supported by the Singapore Ministry of Health's National Medical Research Council under the Centre Grant Programme (Grant No.: NMRC/CG/004/2013). Dr. Jimmy Lee is supported by the National Healthcare Group's Clinician Scientist Career Scheme.

\section{REFERENCES}

1. Pertwee RG. Cannabinoid pharmacology: the first 66 years. Br J Pharmacol 2006;147 Suppl 1:S163-S171.

2. Koppel BS, Brust JC, Fife T, Bronstein J, Youssof S, Gronseth G, et al. Systematic review: efficacy and safety of medical marijuana in selected neurologic disorders: report of the Guideline Development Subcommittee of the American Academy of Neurology. Neurology 2014;82:1556-1563.

3. Whiting PF, Wolff RF, Deshpande S, Di Nisio M, Duffy S, Hernandez AV, et al. Cannabinoids for medical use: A systematic review and meta-analysis. JAMA 2015;313:2456-2473.

4. Ujváry I, Hanuš L. Human metabolites of cannabidiol: a review on their formation, biological activity, and relevance in therapy. Cannabis Cannabinoid Res 2016;1:90-101.

5. Klumpers LE, Beumer TL, van Hasselt JG, Lipplaa A, Karger LB, Kleinloog HD, et al. Novel $\Delta(9)$-tetrahydrocannabinol formulation Namisol R has beneficial pharmacokinetics and promising pharmacodynamic effects. Br J Clin Pharmacol 2012;74:42-53.

6. Ahmed AI, van den Elsen GA, Colbers A, Kramers C, Burger DM, van der Marck MA, et al. Safety, pharmacodynamics, and pharmacokinetics of multiple oral doses of delta-9-tetrahydrocannabinol in older persons with dementia. Psychopharmacology (Berl) 2015;232:2587-2595.

7. Sagredo O, García-Arencibia M, de Lago E, Finetti S, Decio A, Fernández-Ruiz J. Cannabinoids and neuroprotection in basal ganglia disorders. Mol Neurobiol 2007;36:82-91.

8. Kluger B, Triolo P, Jones W, Jankovic J. The therapeutic potential of cannabinoids for movement disorders. Mov Disord 2015;30:313-327.

9. Leweke FM, Mueller JK, Lange B, Rohleder C. Therapeutic potential of Cannabinoids in psychosis. Biol Psychiatry 2016;79:604-612.

10. Rohleder C, Müller JK, Lange B, Leweke FM. Cannabidiol as a potential new type of an antipsychotic. A critical review of the evidence. Front Pharmacol 2016;7:422.

11. Iseger TA, Bossong MG. A systematic review of the antipsychotic properties of cannabidiol in humans. Schizophr Res 2015;162:153-161.

12. Higgins JP, Altman DG, Gøtzsche PC, Jüni P, Moher D, Oxman $\mathrm{AD}$, et al. The Cochrane Collaboration's tool for assessing risk of bias in randomised trials. BMJ 2011;343: d5928.

13. Gross H, Ebert MH, Faden VB, Goldberg SC, Kaye WH, Caine ED, et al. A double-blind trial of delta 9-tetrahydrocannabinol in primary anorexia nervosa. J Clin Psychopharmacol 1983;3:165-171.

14. Andries A, Frystyk J, Flyvbjerg A, Støving RK. Dronabinol in severe, enduring anorexia nervosa: a randomized controlled trial. Int J Eat Disord 2014;47:18-23.

15. Fabre LF, McLendon D. The efficacy and safety of nabilone 
(a synthetic cannabinoid) in the treatment of anxiety. J Clin Pharmacol 1981;21(8-9 Suppl):377S-382S.

16. Glass RM, Uhlenhuth EH, Hartel FW, Schuster CR, Fischman MW. Single-dose study of nabilone in anxious volunteers. J Clin Pharmacol 1981;21(8-9 Suppl):383S-396S.

17. Zuardi AW, Shirakawa I, Finkelfarb E, Karniol IG. Action of cannabidiol on the anxiety and other effects produced by delta 9-THC in normal subjects. Psychopharmacology (Berl) 1982;76:245-250.

18. Bergamaschi MM, Queiroz RH, Chagas MH, de Oliveira DC, De Martinis BS, Kapczinski F, et al. Cannabidiol reduces the anxiety induced by simulated public speaking in treatment-naïve social phobia patients. Neuropsychopharmacology 2011;36: 1219-1226.

19. Crippa JA, Derenusson GN, Ferrari TB, Wichert-Ana L, Duran FL, Martin-Santos R, et al. Neural basis of anxiolytic effects of cannabidiol (CBD) in generalized social anxiety disorder: a preliminary report. J Psychopharmacol 2011; 25:121-130

20. Jetly R, Heber A, Fraser G, Boisvert D. The efficacy of nabilone, a synthetic cannabinoid, in the treatment of PTSD-associated nightmares: a preliminary randomized, double-blind, placebo-controlled cross-over design study. Psychoneuroendocrinology 2015;51:585-588.

21. Leweke FM, Piomelli D, Pahlisch F, Muhl D, Gerth CW, Hoyer C, et al. Cannabidiol enhances anandamide signaling and alleviates psychotic symptoms of schizophrenia. Transl Psychiatry 2012;2:e94.

22. Volicer L, Stelly M, Morris J, McLaughlin J, Volicer BJ. Effects of dronabinol on anorexia and disturbed behavior in patients with Alzheimer's disease. Int J Geriatr Psychiatry 1997;12:913-919.

23. Walther S, Schüpbach B, Seifritz E, Homan P, Strik W. Randomized, controlled crossover trial of dronabinol, 2.5 $m g$, for agitation in 2 patients with dementia. J Clin Psychopharmacol 2011;31:256-258.

24. van den Elsen GA, Ahmed AI, Verkes RJ, Kramers C, Feuth $\mathrm{T}$, Rosenberg $\mathrm{PB}$, et al. Tetrahydrocannabinol for neuropsychiatric symptoms in dementia: A randomized controlled trial. Neurology 2015;84:2338-2346.

25. van den Elsen GA, Ahmed AI, Verkes RJ, Feuth T, van der Marck MA, Olde Rikkert MG. Tetrahydrocannabinol in behavioral disturbances in dementia: A crossover randomized controlled trial. Am J Geriatr Psychiatry 2015;23:1214-1224.

26. Weber M, Goldman B, Truniger S. Tetrahydrocannabinol (THC) for cramps in amyotrophic lateral sclerosis: a randomised, double-blind crossover trial. J Neurol Neurosurg Psychiatry 2010;81:1135-1140.

27. Fox SH, Kellett M, Moore AP, Crossman AR, Brotchie JM. Randomised, double-blind, placebo-controlled trial to assess the potential of cannabinoid receptor stimulation in the treatment of dystonia. Mov Disord 2002;17:145-149.

28. Zadikoff C, Wadia PM, Miyasaki J, Chen R, Lang AE, So
J, et al. Cannabinoid, CB1 agonists in cervical dystonia: failure in a phase IIa randomized controlled trial. Basal Ganglia 2011;1:91-95.

29. Consroe P, Laguna J, Allender J, Snider S, Stern L, Sandyk $\mathrm{R}$, et al. Controlled clinical trial of cannabidiol in Huntington's disease. Pharmacol Biochem Behav 1991;40:701-708.

30. Curtis A, Mitchell I, Patel S, Ives N, Rickards H. A pilot study using nabilone for symptomatic treatment in Huntington's disease. Mov Disord 2009;24:2254-2259.

31. López-Sendón Moreno JL, García Caldentey J, Trigo Cubillo P, Ruiz Romero C, García Ribas G, Alonso Arias $\mathrm{MA}$, et al. A double-blind, randomized, cross-over, placebocontrolled, pilot trial with Sativex in Huntington's disease. $J$ Neurol 2016;263:1390-1400.

32. Sieradzan KA, Fox SH, Hill M, Dick JP, Crossman AR, Brotchie JM. Cannabinoids reduce levodopa-induced dyskinesia in Parkinson's disease: a pilot study. Neurology 2001;57:2108-2111.

33. Carroll CB, Bain PG, Teare L, Liu X, Joint C, Wroath C, et al. Cannabis for dyskinesia in Parkinson disease: a randomized double-blind crossover study. Neurology 2004; 63:1245-1250.

34. Chagas MH, Zuardi AW, Tumas V, Pena-Pereira MA, Sobreira ET, Bergamaschi MM, et al. Effects of cannabidiol in the treatment of patients with Parkinson's disease: an exploratory double-blind trial. J Psychopharmacol 2014; 28:1088-1098.

35. Müller-Vahl KR, Schneider U, Koblenz A, Jöbges M, Kolbe $\mathrm{H}$, Daldrup T, et al. Treatment of Tourette's syndrome with Delta 9-tetrahydrocannabinol (THC): a randomized crossover trial. Pharmacopsychiatry 2002;35:57-61.

36. Müller-Vahl KR, Schneider U, Prevedel H, Theloe K, Kolbe $\mathrm{H}$, Daldrup T, et al. Delta 9-tetrahydrocannabinol (THC) is effective in the treatment of tics in Tourette syndrome: a 6-week randomized trial. J Clin Psychiatry 2003;64:459-465.

37. Moher D, Liberati A, Tetzlaff J, Altman DG, The PG. Preferred reporting items for systematic reviews and meta-analyses: The PRISMA statement. PLoS Med 2009; 6:e1000097.

38. Zuardi AW, Hallak JE, Dursun SM, Morais SL, Sanches RF, Musty RE, et al. Cannabidiol monotherapy for treatmentresistant schizophrenia. J Psychopharmacol 2006;20:683-686.

39. Zuardi AW, Morais SL, Guimarães FS, Mechoulam R. Antipsychotic effect of cannabidiol. J Clin Psychiatry 1995; 56:485-486.

40. Bhattacharyya S, Morrison PD, Fusar-Poli P, Martin-Santos R, Borgwardt S, Winton-Brown T, et al. Opposite effects of delta-9-tetrahydrocannabinol and cannabidiol on human brain function and psychopathology. Neuropsychopharmacology 2010;35:764-774

41. Wang T, Collet JP, Shapiro S, Ware MA. Adverse effects of medical cannabinoids: a systematic review. CMAJ 2008; 178:1669-1678. 